\title{
Initial experience with a novel resection and plication (RAP) method for acid reflux: a pilot study $\square$
}

\section{(잉 $\odot$}

\author{
Authors \\ Miller ${ }^{1}$, David L. Carr-Locke ${ }^{3}$ \\ Institutions \\ 1 Zucker School of Medicine at Hofstra/Northwell \\ 2 Mount Sinai Beth Israel, New York, New York \\ 3 New York Presbyterian Cornell, New York, New York
}

Petros C. Benias ${ }^{1}$, Lionel D’Souza², Gloria Lan², Craig Gluckman², Sumant Inamdar ${ }^{1}$, Arvind J. Trindade ${ }^{1}$, Larry S.

submitted 21.10 .2017

accepted after revision 27.12 .2017

\section{Bibliography}

DOI https://doi.org/10.1055/s-0044-101453 |

Endoscopy International Open 2018; 06: E443-E449

(c) Georg Thieme Verlag KG Stuttgart · New York ISSN 2364-3722

\section{Corresponding author}

Petros C. Benias, Director of Endoscopic Surgery, Assistant Professor of Medicine, Division of Gastroenterology, Hofstra University, Northwell Health System

Fax: +1-516-387-3990

PBenias@Northwell.edu

\section{ABSTRACT}

Background and study aims Current endoscopic therapies for gastroesophageal reflux disorder (GERD) are limited by technical complexity, and/or cost. We sought to evaluate the success of a novel resection and plication (RAP) anti-reflux procedure.

Patients and methods RAP was performed on 10 patients with GERD refractory to proton pump inhibitor (PPI) therapy. RAP consists of semi-circumferential mucosectomy along with full-thickness plication of the lower esophageal sphincter (LES) and cardia. We assessed the technical success and safety as well as followed GERD-Health Related Quality of Life (GERD-HRQL) scores and medication usage. Results All patients underwent RAP without adverse events and were discharged on the same day. Only half of the patients required general anesthesia. Follow-up ranged from 5 to 24 months (median 9 months) and all patients had a significant improvement in their GERD-HRQL scores $(P<0.0001,95 \% \mathrm{Cl} 19.3-25.3)$. 8 of 10 eliminated their daily PPI dependence.

Conclusions The RAP method has potential as an effective anti-reflux option. Its main advantages include a short procedure time, simple approach using readily available equipment, and possible avoidance of general anesthesia.

\section{Introduction}

Gastroesophageal reflux disease (GERD) affects approximately one-third of the US population and accounts for approximately $\$ 15$ to $\$ 20$ billion in direct and indirect healthcare costs in the United States [1].

The etiology of GERD is multifactorial, but an essential component is a deficiency of the lower esophageal high-pressure zone (LEHPZ) [2,3] which is critical to functioning of the lower esophageal sphincter (LES) The LES is a multifunctional valve composed of different muscle groups of the distal esophagus, proximal stomach, and extrinsic crural diaphragm [4]. In normal subjects, the LEHPZ of the LES is asymmetrical, with higher pressures centered around the left posterior aspect [5] - the area of the angle of His. This is also where the sling fibers wrap posteriorly as they meet with the more anterolateral clasp fi- bers [4]. In addition, there are overlying structural elements, such as the mucosal flap valve, which are important anti-reflux mechanisms [6].

Certain endoscopic approaches to GERD have been developed, including trans oral incisionless fundoplication (TIF) [79], anti-reflux mucosectomy (ARMS) [10], and endoscopic suturing of the gastroesophageal junction. TIF invaginates tissue along the posterolateral aspect of the LES, elongating the channel and making the angle of His more prominent. TIF has the most supportive long-term data, with $75 \%$ to $80 \%$ of patients able to eliminate use of proton pump inhibitors (PPIs) at 6 years of follow-up $[8,9]$. It is not clear whether TIF is anatomically durable or that initial improvements in $\mathrm{pH}$ persist after the first few months [9]. Alternately, ARMS relies on the phenomenon of stricture formation after mucosectomy to produce a more robust mucosal flap. Inoue et al first reported the use of ARMs in 

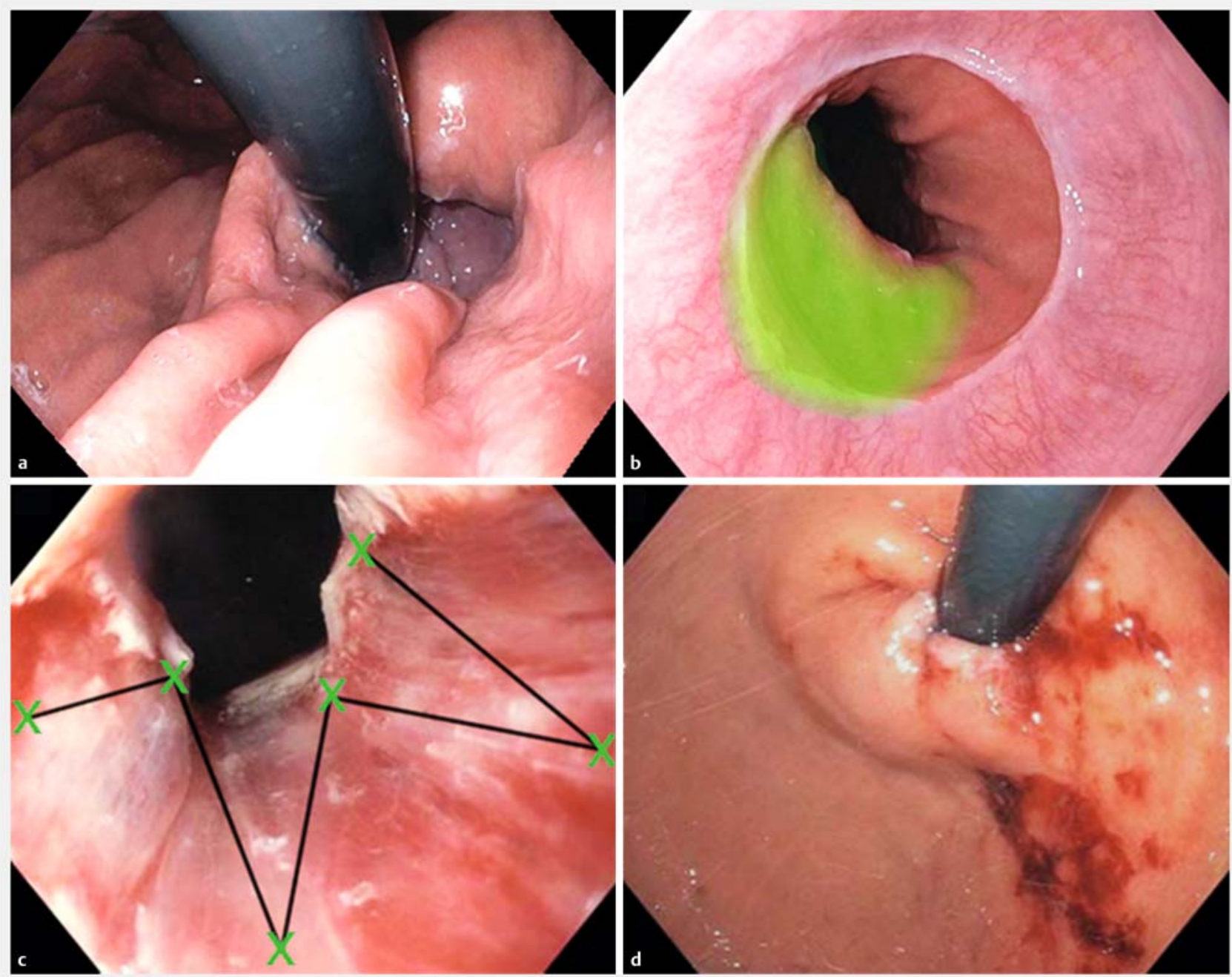

- Fig. 1 Conceptual diagram of a RAP anti-reflux procedure. a Retroflexed view of a patient with a small hiatus hernia, b followed by mucosal resection along the aspect of the greater curvature at the level of the GEJ, and $\mathbf{c}$ finally a full-thickness plication according to a predetermined suture pattern, $\mathbf{d}$ with an improved appearance on retroflexion.

a series of 10 patients, suggesting that an almost completely circumferential mucosectomy would provide adequate relief of acid reflux symptoms [10]. This approach can be technically challenging and has not been well studied. Finally, prior suturing technologies such as EndoCinch (Bard Endoscopic Technologies, Billerica, MA) were limited and did not produce full-thickness sutures, and any attempts at suturing the gastroesophageal junction had good short-term results but poor long-term durability [11].

Wanting to provide a simple and cost-effective approach to GERD, we developed a novel resection and plication (RAP) method, which is based on prior endoscopic therapies that have shown effectiveness. RAP utilizes limited mucosectomy and full-thickness plication of the LES in a predetermined pattern. The aim of this study was to look at our initial experience with this variation on endoscopic suturing of the gastroesophageal junction, and to assess its technical feasibility, safety, and short-term effectiveness. We report results in 10 consecutive patients who have undergone RAP.

\section{Patients and methods}

\section{Patient selection}

Ten patients with symptoms and objective findings of GERD agreed to undergo RAP. Patients were included if they had become refractory to their standard PPI dose and wanted an alternative to increasing their medical therapy. They did not want, or were not fit for, traditional surgery and instead opted to undergo RAP after discussing other non-surgical options, such as Stretta and TIF.

Patients were considered for RAP if they were at least 18 years old and had typical GERD symptoms that did not resolve on a regular or high-dose $\mathrm{PPI}$ regimen ( $\geq 40 \mathrm{mg}$ omeprazole equivalents per day). In addition, patients had to have objective findings of reflux. Patients were selected to have typical GERD 
- Table 1 Patient characteristics.

\begin{tabular}{|c|c|c|c|c|c|c|c|c|}
\hline Subject & $\begin{array}{l}\text { PPI use } \\
\text { before }^{1}\end{array}$ & $\begin{array}{l}\text { GERD- } \\
\text { HRQL } \\
\text { before }\end{array}$ & Supporting studies & $\begin{array}{l}\text { Esophagitis } \\
\text { LA grade }\end{array}$ & $\begin{array}{l}\text { Hiatus } \\
\text { hernia/ } \\
\text { Hill } \\
\text { grade }\end{array}$ & $\begin{array}{l}\text { Duration } \\
\text { of follow- } \\
\text { up }\end{array}$ & $\begin{array}{l}\text { GERD- } \\
\text { HRQL } \\
\text { after }\end{array}$ & $\begin{array}{l}\text { PPI use } \\
\text { after }^{1}\end{array}$ \\
\hline 1 & $40 \mathrm{mg}$ PPI BID & 36 & Barium esophagram & Grade A & $1 \mathrm{~cm} / 1$ & 24 months & 8 & H2B daily \\
\hline 2 & $20 \mathrm{mg}$ PPI BID & 25 & $\begin{array}{l}\text { Barium esophagram } \\
\text { pH Study }\end{array}$ & Grade A & $1 \mathrm{~cm} / 2$ & 21 months & 1 & None \\
\hline 3 & $\begin{array}{l}40 \mathrm{mg} \mathrm{PPI}+ \\
\mathrm{H} 2 \mathrm{~B} \text { daily }\end{array}$ & 22 & Barium esophagram & Grade A & $1 \mathrm{~cm} / 1$ & 16 months & 2 & None \\
\hline 4 & $\begin{array}{l}40 \mathrm{mg} \mathrm{PPI+} \\
\mathrm{H} 2 \mathrm{~B} \text { daily }\end{array}$ & 30 & Barium esophagram & Grade A & $2 \mathrm{~cm} / 2$ & 15 months & 4 & H2B PRN \\
\hline 5 & 40 mg PPI daily & 27 & Barium esophagram & Grade A & $2 \mathrm{~cm} / 2$ & 7 months & 2 & None \\
\hline 6 & 40 mg PPI daily & 27 & $\begin{array}{l}\text { Barium esophagram } \\
\text { pH Study }\end{array}$ & Grade B & $2 \mathrm{~cm} / 2$ & 9 months & 4 & None \\
\hline 7 & 40 mg PPI BID & 25 & Barium esophagram & Grade A & $2 \mathrm{~cm} / 2$ & 9 months & 4 & None \\
\hline 8 & 40 mg PPI daily & 25 & $\begin{array}{l}\text { Barium esophagram } \\
\text { pH Study }\end{array}$ & Grade B & $2 \mathrm{~cm} / 3$ & 6 month & 8 & PPI 20 mg daily \\
\hline 9 & 40 mg PPI daily & 25 & $\begin{array}{l}\text { Barium esophagram } \\
\text { pH Study }\end{array}$ & Grade B & $1 \mathrm{~cm} / 1$ & 5 month & 5 & None \\
\hline 10 & $\begin{array}{l}40 \mathrm{mg} \mathrm{BID}+ \\
\mathrm{H} 2 \mathrm{~B}\end{array}$ & 24 & $\begin{array}{l}\text { Barium esophagram } \\
\text { pH Study }\end{array}$ & None & $1 \mathrm{~cm} / 1$ & 5 month & 5 & $\begin{array}{l}\text { PPI } 20 \text { mg (inter- } \\
\text { mittent use) } \\
\text { H2B PRN }\end{array}$ \\
\hline
\end{tabular}

symptoms, evidence of esophagitis and a positive $\mathrm{pH}$ study (Bravo $\mathrm{pH}$ monitoring system, Medtronic). If $\mathrm{pH}$ testing was not available, we relied on evidence of GERD symptoms, esophagitis and a barium esophagram demonstrating reflux. Patients were not considered for RAP if they had evidence of a primary esophageal dysmotility disorder on esophageal manometry and/or a hiatal hernia greater than $2 \mathrm{~cm}$. In addition, patients were not included in this analysis if they had prior gastric surgery, or were on any form of anticoagulation.

Post-procedure, patients were followed clinically with GERDHRQL scores and documentation of PPI and/or H2 blocker use. They were followed prospectively with a standardized GERDHRQL score at baseline, 1 month, and then every 3 to 6 months, and again at the time of this analysis. Follow-up $\mathrm{pH}$ monitoring or endoscopy was not routinely performed and so was not included. Written consent was obtained from the patients for mucosal resection and endoscopic suturing. All procedures were performed by endoscopists with extensive experience in endoscopic suturing and prior experience with TIF, and EndoCinch. Data on the procedure and patient symptoms were collected prospectively as part of a registry approved by the IRB at the Northwell Health System looking at endoscopic treatments for GERD including RAP. This study was unfunded.

\section{Description of resection and plication (RAP) anti-reflux method}

Using a standard gastroscope, a crescent-shaped mucosectomy was performed using a standard saline injection and snare technique or with a multiband mucosal resection device (Cook Duette) ( $\triangleright$ Fig. 1). Mucosectomy was performed at the level of the gastroesophageal junction along the left posterolateral axis in line with the greater curvature. That positioned the mucosectomy in line with the fundus and angle of His. The resection was approximately $2 \mathrm{~cm}$ in length and ranged from one-third to one-half the circumference in lateral span, leaving the right anterolateral aspect of the gastroesophageal junction intact. In other words, the resection was formed in the area of the supposed sling fibers, and aimed to remove the tissue at the level of the gastroesophageal junction and just below it on the gastric side. Using the Apollo Overstitch (Apollo Endosurgery, Austin, Texas), a single suture (2-0 standard Apollo prolene suture) was directed through the exposed muscle fibers in a fullthickness manner and according to a predetermined pattern as per Fig.1c. Suturing was performed in a forward en face endoscopic view and a tissue grasping device was not required. No reinforcing sutures were required. Antibiotics (cefazolin $2 \mathrm{~g}$ intravenous) were given on a case-by-case basis and was not standardized. In addition, use of general anesthesia was not standardized and was decided upon by the anesthesia staff 

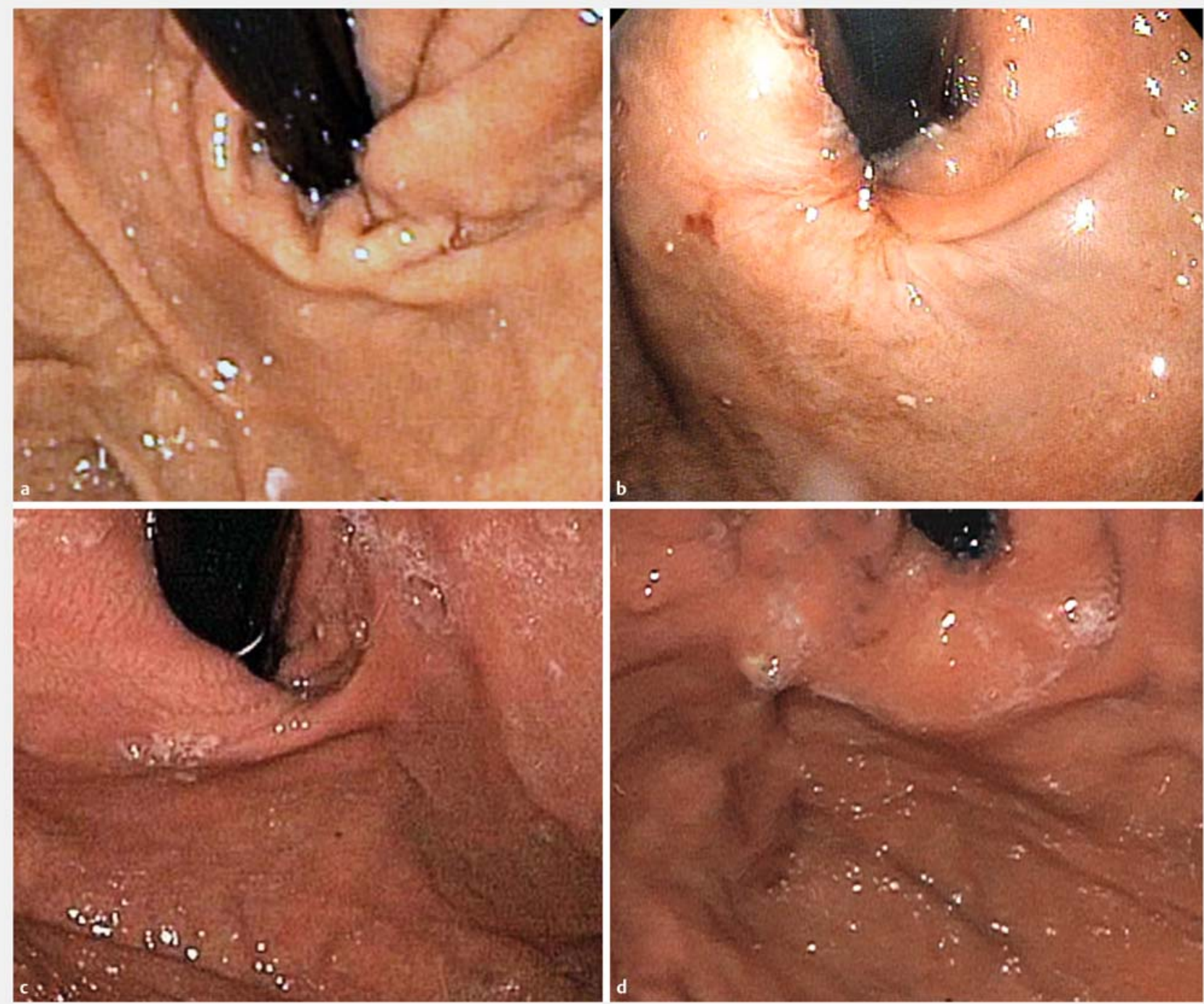

- Fig. 2 Endoscopic appearance of RAP in patients with intermediate and long-term follow-up. a Patient 1 with small HH with follow-up endoscopy at 3.5 months, $\mathbf{b}$ showing improved LES and valvular appearance. $\mathbf{c}$ Patient 2 with small HH and $\mathbf{d}$ with follow-up at 2 years showing durable endoscopic improvement which correlated with her symptom scores.

and based on a patient's comorbidities. General anesthesia was not a requirement to perform this procedure.

\section{Post-procedure care}

Patients were discharged on the same day, with instructions to take a thin-liquid high protein diet for 1 week. They were not discharged with any narcotic pain medications, and were instructed to avoid nonsteroidal anti-inflammatory drugs postprocedure. Afterwards they self-advanced to a soft mechanical diet and on to a normal diet over the following week. Patients were kept on a 40-mg PPI equivalent for 1 week and were instructed to wean off afterwards. They underwent routine follow-up in the office.

\section{Results}

Ten patients agreed to undergo RAP for unresolved or worsening GERD symptoms (9 males, 1 female, average age $=56.5$, average body mass index $=28.1 \pm 2.5$ ) ( Table 1 ). At baseline, the average GERD-HRQL was $26.6 \pm 3.9$. RAP was performed successfully in all 10 patients. There were no mild, moderate or severe adverse events at the time of the procedure or within 48 hours following it [12]. Overall, the procedure was considered safe with the only technical challenge being that one patient required an additional suture in an interrupted fashion to produce the intended pattern. That patient developed intermittent dysphagia at 1 month related to a mild stricture and was treated with dilation.

The final valve appearance in all cases was that of a Hill grade I. The combination of mucosectomy and plication could be completed in an average time of 44 minutes (range 27 - 


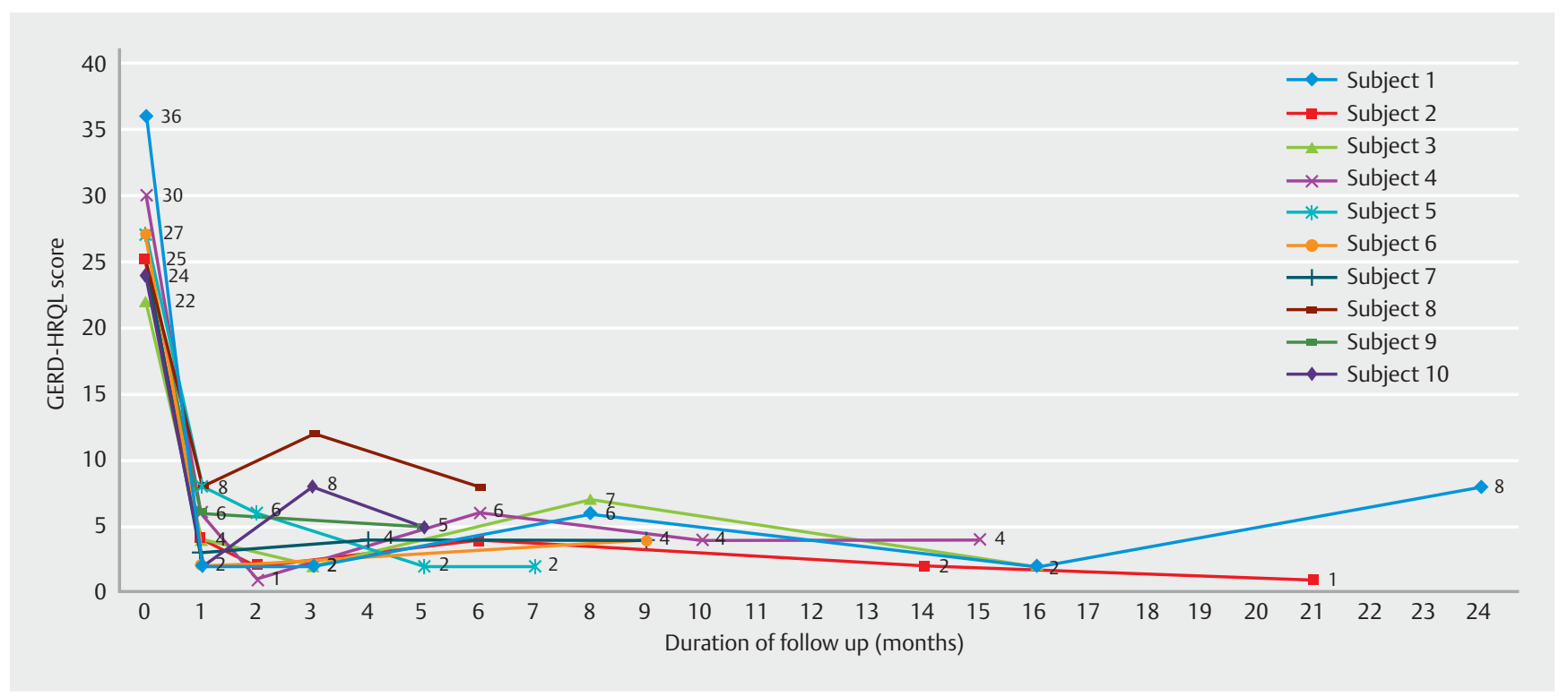

- Fig. 3 Change over time on GERD-HRQL scores on a per-patient basis.

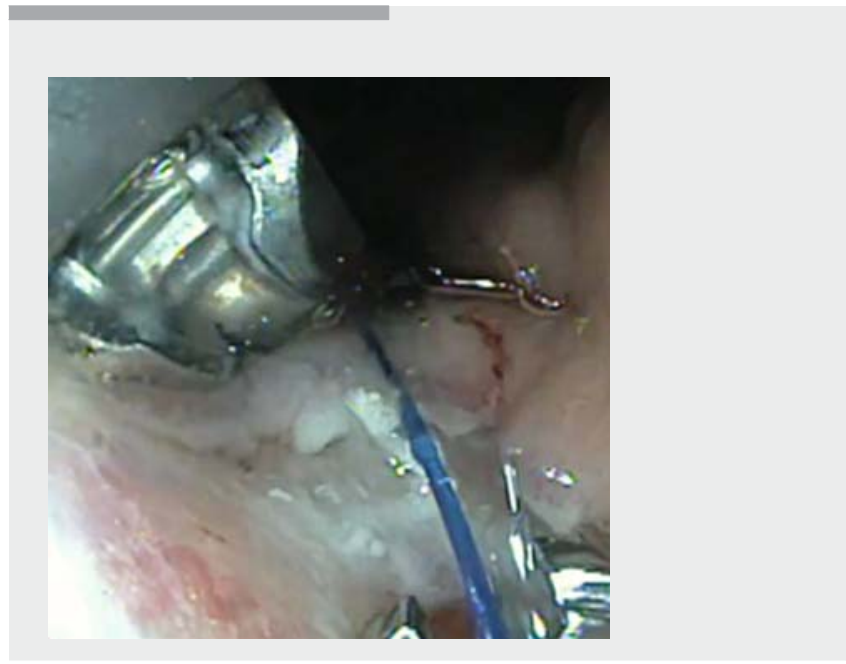

Video 1 Demonstration of RAP anti-reflux method. Patient with reflux esophagitis and a small hiatus hernia. Mucosectomy performed along posterior GE junction using a band EMR technique. Valve is sutured according to a predetermined pattern ( Fig. 1).

$60)$, and only five patients required general anesthesia due to comorbidities. In the remainder of the patients, moderate sedation was sufficient. None of the patients required any postprocedure narcotics and all patients were able to be safely discharged on the same day.

In 8 of 10 patients, daily dependence on PPIs was eliminated. Of them, two reported using $\mathrm{H} 2$ blockers periodically during follow-up. Of the patients that resumed PPI use, it was generally less than their pre-procedure baseline. At the time of this analysis, the mean GERD-HRQL score was $4.3 \pm 2.4$. The difference in GERD-HRQL before and after RAP was highly significant (absolute reduction 22.3, $P<0.0001,95 \% \mathrm{Cl} 19.3-25.3$ ). Medi- an follow-up was 9 months (range 5-24), and four patients had follow-up greater than 1 year. Several patients had follow-up endoscopies for other reasons. The appearance of a RAP at various time points including 2 years appeared durable in the few patients with follow-up endoscopies (> Fig.2). GERD-HRQL scores are shown over time in $\mathbf{F i g .} \mathbf{3}$ and a RAP procedure is shown in $>$ Video 1.

\section{Conclusions}

Recent epidemiologic evidence suggests that PPIs are associated with adverse side effects ranging from osteoporosis to an increase in incidence of dementia, chronic renal failure and even inpatient death [13]. Therefore, it is important that effective substitute treatments for GERD be developed.

The RAP anti-reflux procedure is a novel integration of past methods for acid reflux but is unique in its simplicity and ability to target the main anatomical deficiencies of the LES. As with other endoscopic approaches, we selected patients with small hiatal hernias and no evidence of large crural defects. When there is no significant crural defect, the valvular mechanism is more likely to play a role, which implies that recreating the angle of His, the length of the LES channel, the mucosal flap and the high-pressure zone in the left posterolateral quadrant should be the focus of an endoscopic approach. RAP attempts to address all of these and appears to be successful, although more long-term studies will be required.

Regarding our selection of patients, we included patients who had typical symptoms of GERD and objective findings of it. This was an unfunded study and $\mathrm{pH}$ monitoring was not routinely performed either due to costs or patient preference. Nonetheless, 9 of 10 patients had endoscopic evidence of reflux esophagitis and a barium esophagram consistent with GERD, and 5 patients did have formal $\mathrm{pH}$ monitoring before the procedure. The concordance of esophagitis, symptoms, and other objective data, while not standardized, suggests 
that we are dealing with a cohort of patients who have GERD $[14,15]$. This is a limitation of the current study that will need to be addressed in the future. During post-procedure follow-up we relied on GERD-HRQL scoring and assessment of medication usage to look for a benefit. Cessation of PPI use can be considered an excellent marker of response independent of post-procedure $\mathrm{pH}$ data and GERD-HRQL scores.

Regarding the technical aspects of this procedure, we believe that it was both safe and straightforward with few technical challenges. The proceduralists were all experts in endoscopic suturing and had experience with suturing at the gastroesophageal junction. In addition, we felt that mucosectomy was easier to perform using a multiband endoscopic mucosal resection (EMR) approach and that was used as the standard approach after the first five cases. The extent of EMR was also important for us as it inevitably dictated subsequent suturing and reduction in the valve area. About one-third of the valve circumference was resected, with the exception that in two patients with $2-\mathrm{cm}$ hernias we resected up to one-half of the total circumference. The extent of mucosectomy and whether that may result in dysphagia will need to be further studied in the future.

It is difficult to make any strong statements about the efficacy or durability of this technique given the small number of patients who are at various points in their follow-up. However, it is interesting to note that in our series the majority of patients (8) 10) were able to discontinue use of daily PPIs and had a significant reduction in GERD-HRQL scores. Median follow-up was only 9 months, so it is difficult at this time to know the durability of this procedure with respect to endoscopic appearance and GERD symptoms. In the few patients with follow-up endoscopies, the appearance as far out as 2 years suggests that this may be durable ( $>$ Fig. 2 ). That needs to be addressed in a larger study, to assess both symptoms and post-procedure $\mathrm{pH}$ and the durability of reconstruction of the valve.

The RAP anti-reflux procedure is appealing because in many cases it can be performed in a relatively short period of time. In addition, it does not require general anesthesia as do TIF and MUSE and nor does it require working in the retroflexed position. That may prove to be an important option for patients with altered gastric anatomy, especially those with a sleeve gastrectomy. Also, patients did not experience any pain and were all safely discharged on the same day. The combination of a semi-circumferential mucosectomy and full-thickness plication allows us to dynamically remodel the valve. This procedure not only seems to decrease the final valve diameter but also recreates the angle of His and mucosal flap valve. Unlike ARMs, it does not rely entirely on the formation of a scar and unlike TIF it does not require complex equipment or second operators. RAP does not seem to simply produce a stricture, but as has been shown in past studies of suturing, it may provide more integrity to the sling/clasp fiber mechanism [16].

In future studies, we will need to understand whether symptomatic and pharmacologic improvements correlate with reduced acid exposure objectively. It will also be important, given new technology such as EndoFlip, to understand how this type of procedure affects valve compliance.

\section{Conclusion}

RAP's technical ease and our promising early results may the procedure a promising alternative for a widespread health problem. In addition, it may be one of the few anti-reflux options available for patients with altered gastric anatomy such as with sleeve gastrectomy, given that no retroflexion is required. Therefore, future studies will need to focus on all of the potential applications of RAP in specialized GERD populations.

\section{Competing interests}

None

References

[1] Gawron AJ, French DD, Pandolfino JE et al. Economic evaluations of gastroesophageal reflux disease medical management. Pharmacoeconomics 2014; 32: $745-758$

[2] Miller LS, Vegesna AK, Brasseur JG et al. The esophagogastric junction Ann. N.Y. Acad. Sci 2011; 1232: 323-330

[3] Miller L, Vegesna A, Kalra A et al. New Observations on the Gastroesophageal Antireflux Barrier. Gastroenterol Clin N Am 2007; 36: $601-617$

[4] Brasseur JG, Ulerich R, Dai Q et al. Pharmacological dissection of the human gastro-oesophageal segment into three sphincteric components. J Physiol 2007; 580: $961-975$

[5] Winans CS. Manometric asymmetry of the lower-esophageal highpressure zone. Am J Dig Dis 1977; 22: 348-354

[6] Menezes MA, Herbella FA. Pathophysiology of gastroesophageal reflux disease. World J Surg 2017; 41: 1661-1671

[7] Huang $X$, Chen $S$, Zhao $H$ et al. Efficacy of transoral incisionless fundoplication (TIF) for the treatment of GERD: a systematic review with meta-analysis. Surg Endosc 2017; 31: 1032 - 1044

[8] Testoni PA, Testoni S, Mazzoleni G et al. Long-term efficacy of transoral incisionless fundoplication with Esophyx (Tif 2.0) and factors affecting outcomes in GERD patients followed for up to 6 years: a prospective single-center study. Surg Endosc 2015; 29: 2770-2780

[9] Witteman BP, Conchillo JM, Rinsma NF et al. Randomized controlled trial of transoral incisionless fundoplication vs. proton pump inhibitors for treatment of gastroesophageal reflux disease. Am J Gastroenterol 2015; 110: $531-542$

[10] Inoue $\mathrm{H}$, Ito $\mathrm{H}$, Ikeda $\mathrm{H}$ et al. Anti-reflux mucosectomy for gastroesophageal reflux disease in the absence of hiatus hernia: a pilot study. Ann Gastroenterol 2014; 27: 346-351

[11] Ozawa S, Kumai K, Higuchi K et al. Short-term and long-term outcome of endoluminal gastroplication for the treatment of GERD: the first multicenter trial in Japan. J Gastroenterol 2009; 44: 675-684

[12] Cotton PB, Eisen GM, Aabakken L et al. A lexicon for endoscopic adverse events: report of an ASGE workshop. Gastrointest Endosc 2010; 71: $446-454$

[13] Schnoll-Sussman F, Katz PO. Clinical implications of emerging data on the safety of proton pump inhibitors. Curr Treat Options Gastroenterol 2017; 15: 1 - 9

[14] Madan K, Ahuja V, Gupta SD et al. Impact of 24-h esophageal pH monitoring on the diagnosis of gastroesophageal reflux disease: defining the gold standard. J Gastroenterol Hepatol 2005; 20: 30-37 
[15] Fass R, Ofman JJ, Sampliner RE et al. The omeprazole test is as sensitive as 24-h oesophageal $\mathrm{pH}$ monitoring in diagnosing gastro-oesophageal reflux disease in symptomatic patients with erosive oesophagitis. Aliment Pharmacol Ther 2000; 14: 389-396
[16] Dai Q, Brasseur JG, Dimitriou J et al. 2-D and 3-D endoluminal ultrasound localization of endoscopic plications with simultaneous manometry. Gastrointest Endosc 2004; 59: 244 